patients are available. The potential impact of the effects of lipid lowering on morbidity and morality in patients with coronary artery disease was highlighted by the Scandinavian Simvastatin Survival Study $(4 S)^{[7]}$. Patients with preserved exercise capacity are often not considered for cardiac rehabilitation programmes. However, aside from learning how to cope with the limitations imposed by the present state of the disease, a second thrust of cardiac rehabilitation is to prevent progression of the disease and future deterioration of the quality of life by appropriate life style changes and medical treatment ${ }^{[8]}$. This can be achieved by a multifactorial comprehensive approach, as was shown by Haskell $e t$ al. ${ }^{[9]}$, and also by lipid lowering ${ }^{[7]}$, in a low risk group of patients with coronary artery disease.

Bypass surgery and PTCA are palliative procedures. To improve prognosis on a long-term basis the underlying disease process needs to be altered to retard progression, induce regression and prevent future events. Various treatment measures ${ }^{[-9]}$ which are effective in achieving these goals can all be optimally applied in a comprehensive rehabilitation programme. Thus, cardiac rehabilitation with its multifactorial and multidisciplinary approacb has gained greater importance, even in patients suffering minimal distress and in those with preserved exercise capacity.

European Heart Journal (1995) 16, 1022-1023

\section{References}

[1] Homback AM, Sawe U, Fagher B. Training after myocardial infarction: lack of long-term effects on physical capacity and psychological variables. Arch Phys Med Rehabil 1994; 75: $551-4$.

[2] Worcester MC, Hare DL, Oliver RG, Reid MA, Goble AJ. Early programmes of high and low intensity exercise and quality of life after acute myocardial infarction. Br Med J 1993; 307: 1244-7.

[3] Denollet J, Brutsaert DL. Enhancing emotional well-being by comprehensive rehabilitation in patients with coronary heart disease. Eur Heart J 1995; 16: 1070-8.

[4] Williams RB, Chesney MA Psycho-social factors and prognosis in established coronary artery disease. The need for research on interventions. JAMA 1993; 270: 1860-1.

[5] Lavie CJ, Milanı RV, Lıttman AB. Benefits of cardıac rehabilitation and exercise trainıng in secondary coronary prevention in the elderly. J Am Coll Cardiol 1993; 22: 678-83.

[6] Lavie CJ, Milani RV, Boykin C. Effects of cardiac rehabilitation and exercise training on coronary risk factors and quality of life in women (Abstract). J Am Coll Cardiol 1994; 23: 50A.

[7] Scandinavian Simvastatin Survival Study Group. Randomised trial of cholesterol lowering in 4444 patients with coronary heart disease: the Scandinavian Simvastatin Survival Study. Lancet 1994; 344: 1383-9.

[8] Task force of the Working Group on Cardiac Rehabllitation of the European Soclety of Cardiology. Long-term comprehensive care of cardiac patients - recommendations by the Working Group on Rehabilitation of the ESC, Cardiac Rehabilitation: Definitıon and Goals. Eur Heart J 1992; 13 (Suppl C): 1-2.

[9] Haskell WL, Alderman EL, Fair JM et al Effects of multiple risk factor reduction on coronary atherosclerosis and clinical cardiac events in men and women with CAD - The Stanford Coronary Risk Intervention Project Circulation 1994; 89: 975-90.

\title{
Balloon or blade for calcified mitral stenosis
}

\author{
C. RÖTHLISBERGER
}

Cardiology, University Hospital, Bern, Switzerland

The elderly patient suffering from mitral stenosis represents a challenge to every cardiologist if the patient becomes severely symptomatic despite adequate medical therapy. If there is associated cardiac and non-cardiac disease, operative mortality as a result of surgical commissurotomy or even mitral valve replacement is clearly increased. On the other hand, a severely altered valve morphology with heavy calcifications is frequently found in older patients and limits short- and long-term success of balloon commissurotomy. For the clinician it is therefore important to know which subset of patients would still profit from balloon commissurotomy. As a direct comparison of surgical vs balloon commissurotomy in this age group is unfeasible and unethical (surgery is often not an option), our knowledge has to be based on retrospective studies. Such a retrospective study is presented by Iung et al. ${ }^{[1]}$ in this issue and sheds some light on the problems of differential therapy of calcified mitral stenosis. The important findings are: (1) A total of $36 \%$ of the referred patients were excluded from percutaneous balloon commissurotomy due to either associated cardiac disease requiring surgery or bicommissural calcifications. The latter was the only morphological criteria used to exclude patients from the 
procedure apart from the usual contraindications. As commissural splitting in the presence of commissural calcification cannot be expected, such a decision seems reasonable. If no commissural splitting can be achieved, the initial result will be unsatisfactory ${ }^{[2]}$. (2) Although the procedure is technically feasible in elderly patients the complication rate regarding procedure-related death, in-hospital mortality, pericardial tamponade, thromboembolism, severe mitral regurgitation and need for surgical repair at the puncture site is substantial. This finding is in accordance with other reports demonstrating relevant complications in the range of $16-27 \% \%^{[3,4]}$ compared to $8 \%$ in the younger population in the NHLBI registry ${ }^{\text {[I] }}$. (3) A sizeable percentage of poor immediate results is to be expected varying from 28 $53 \%{ }^{[1,3,4]}$. As the definition of a poor result differs among various studies (usually mitral valve area $>1.5 \mathrm{~cm}^{2}$ and mitral regurgitation $\leq 2+$ ), a direct comparison is difficult. The predictors of a poor outcome in this age group are extensive valve calcification and prior surgical commissurotomy in Iung's study. Other reports revealed a smaller mitral valve area before the intervention, a higher pulmonary resistance and the combination of low echocardiographic score, low NYHA functional class and inverse mitral valve area as the best predictors of success $^{[3,4]}$. The prevalence of all these parameters is strongly influenced by the duration and the extent of the disease. Elderly patients will obviously have accumulated multiple adverse factors since the time their disease started with a rheumatic fever. (4) The long-term result, defined as freedom from death, reintervention or surgery, after balloon commissurotomy in this age group is moderate; the event-free survival after 4 years was $54 \pm 17 \%$. An event-free survival together with a good functional result (NYHA functional class I or II) after 4 years was found in $34 \pm 16 \%$ only, which is similar to Tuzcu's study ( $46 \pm 7 \%$ after 3 years). A low NYHA class, a low echocardiographic mitral valve score, lack of calcification of the mitral valve, a good immediate result, low left atrial, pulmonary artery and left ventricular end diastolic pressures have all been shown to predict an event-free survival ${ }^{[1,4,6]}$. Again, all these predictive parameters are either a sign of advanced mitral valve disease or are critically influenced by associated cardiac disorders, such as coronary artery disease which is highly prevalent in this age group in a Western society. The clinical follow-up is therefore determined by the unfavourable valve anatomy resulting in a significant percentage of suboptimal results, with an increased risk of restenosis on the one hand, and the extent of concomitant disorders on the other. (5) The peri-operative mortality of the patients undergoing mitral valve replacement during the follow-up period is $20 \%$, highlighting the fact that surgery is often not the ideal procedure in this age group. The specific valve prosthesis-related side effects and complications will further influence the long-term outcome in these operated patients.

Thus, balloon commissurotomy in the elderly patient is above all a palliative procedure with an increased complication rate, and acceptable immediate and moderate long-term results. Nevertheless this procedure is a practicable alternative to a surgical intervention in the severely symptomatic, elderly patient with predominantly calcified mitral stenosis. The best results will be achieved in patients with minimal calcifications in the absence of concomitant disorders. But even if significant calcifications are present, balloon commissurotomy can at least produce a temporary clinical improvement, as long as the calcifications are not located in both commissures. In the case of bicommissural calcifications, surgery with mitral valve replacement seems to be the only reasonable option, but carries an increased risk of untoward events. Between the clearcut indications for either surgery with valve replacement or balloon commissurotomy lies a gray zone where careful weighing of the pros and cons in relation to a specific patient is essential. Together with the patient's preference and the knowledge of the merits of the two procedures a well balanced decision about the way to proceed must be reached for each patient.

\section{References}

[1] Iung B, Cormier, B, Farah B, Nallet O, Porte JM et al. Percutaneous mitral commissurotomy in the elderly. Eur Heart J 1995; 16: 1092-9.

[2] Fatkin D, Roy P, Morgan JJ and Fenely MP. Percutaneous balloon mitral valvotomy with the Inoue single-balloon catheter: Commissural morphology as a determinant of outcome. J Am Coll Cardiol 1993; 21: 390-7.

[3] Le Feuvre C, Bonan R, Lachurie ML, Leclerc Y, Petitclerc R et al. Balloon mitral commissurotomy in patients aged $\geq 70$ years. Am J Cardiol 1993; 71: 233-6.

[4] Tuzcu EM, Block PC, Griffin BP, Newell JB, Palacios IF. Immediate and long-term outcome of percutaneous mitral valvotomy in patients 65 years and older. Circulation 1992; 85 : 963-71.

[5] The National Heart, Lung and Blood Institute Balloon Valvuloplasty Registry Participants: Multicenter experience with balloon mitral commissurotomy: NHLBI balloon valvuloplasty registry report in immediate and 30 -day follow-up results. Circulation 1992; 85: 448-61.

[6] Cohen DJ, Kuntz RE, Gordon SPF, Piana RN, Safian RD et al. Predictors of long-term outcome after percutaneous balloon mitral valvuloplasty. N Engl J Med 1992; 327:1329-35. 